\title{
The genus Gyrodonta Cameron, with description of a new species and a key to species (Hymenoptera, Ichneumonidae, Ichneumoninae)
}

\author{
Mao-Ling Sheng', Zhen-Qiang Cui', Matthias Riedel² \\ I General Station of Forest Pest Management, State Forestry Administration, 58 Huanghe North Street, Shen- \\ yang 110034, P.R. China 2 Amselweg 9A, 29683 Bad Fallingbostel, Germany \\ Corresponding author: Mao-Ling Sheng (shengmaoling@163.com)
}

Academic editor: Gavin Broad| Received 16 April 2015 | Accepted 17 June 2015 | Published 7 September 2015

http://zoobank.org/B074B63D-C75F-4779-8828-2C1DCEAD7EDD

Citation: Sheng M-L, Cui Z-Q, Riedel M (2015) The genus Gyrodonta Cameron, with description of a new species and a key to species (Hymenoptera, Ichneumonidae, Ichneumoninae). Journal of Hymenoptera Research 45: 87-95. doi: 10.3897/JHR.45.5114

\begin{abstract}
A new species, Gyrodonta motuoica sp. n., collected from Motuo County, Xizang Autonomous Region, China is described. Gyrodonta concava (Uchida, 1937), previously known from Jiangxi, is reported from Hunan Province, China, and Nepal for the first time. Illustrations of both species are provided, as well as a key to species.
\end{abstract}

\section{Keywords}

Ichneumoninae, Gyrodonta, new species, taxonomy, key

\section{Introduction}

Gyrodonta Cameron, 1901, belonging to the tribe Ichneumonini of the subfamily Ichneumoninae (Hymenoptera: Ichneumonidae) and distributed in the Oriental Region, comprises two species (Yu et al. 2012), one of which, G. concava (Uchida, 1937), is from Jiangxi Province, China, and one, G. flavomaculata Cameron, 1901 is from India.

Gyrodonta was originally placed in its own tribe because it is so unusual-looking, distinctive within Ichneumoninae (Cameron, 1901). But Narayanan and Lal (1958) 
included it in the tribe Ichneumonini. Townes et al. (1961) transferred Pielia concava Uchida, 1937 to Gyrodonta and kept it in their tribe Joppini (Ichneumonini of other authors) in their reclassification of Indo-Australian Ichneumonidae. Gupta (1987) followed Schmiedeknecht's (1902) opinion, as a valid tribe Gyrodontini. Wahl and Mason (1995) used out Gyrodontina Schmiedeknecht, 1902 as a valid subtribe within the Ichneumonini. In the "world catalogue" (Yu and Horstmann 1997) and database (Yu, Achterberg and Horstmann 2012), Gyrodonta Cameron was again included in the Ichneumonini, as they do not list subtribes. We agree with Wahl \& Mason's standpoint, Gyrodonta Cameron, 1901 belongs to the subtribe Gyrodontina within the tribe Ichneumonini.

In this article, one new Gyrodonta species, collected in Xizang Autonomous Region, China, and another species, collected in Hunan and in Nepal, previously known from Jiangxi, are described.

\section{Material and methods}

The holotype of Gyrodonta motuoica sp. n. was collected by Tao Li in Motuo County, Xizang Autonomous Region (China) on a blacklit sheet at night. The specimens of $G$. concava (Uchida, 1937) were collected by Ze-Jian Li (Lab of Insect Systematics and Evolutionary Biology, Central South University of Forestry and Technology, Changsha, China) using entomological nets in the forest of Mufushan, Hunan Province (CHINA) and by P. Cechovsky using a Malaise trap in Nepal.

Images were taken using a Leica M205A Stereomicroscope with LAS Montage MultiFocus.

All specimens, except one of G. concava from Nepal in the Biozentrum Linz, Austria, are deposited in the Insect Museum, General Station of Forest Pest Management (GSFPM), State Forestry Administration, People's Republic of China.

\section{Taxonomic section}

\section{Gyrodonta Cameron, 1901}

Gyrodonta Cameron, 1901: 485. Type-species: Gyrodonta flavomaculata Cameron.

Diagnosis. Head large, broad, greatly expanded behind the eyes. Inner margins of eyes parallel. Face wide, slightly concave, upper margin strongly elevated. Clypeal suture indistinct. Apical margin of clypeus slightly evenly convex forwards. Malar space wide. Gena broad. Mandible short, broad, apical portion bluntly rounded, without teeth; upper side with a strong tooth subbasally or near the middle; with basal transverse groove. Areolet pentagonal. Fore wing with vein 1cu-a opposite or distal of 1-M. Scutellum almost flat. Propodeum elongate, incompletely areolated; dorsal profile much longer 
than posterior oblique profile. Spiracle elongate, curved. Legs stout; lower profiles of tarsomeres 1 to 4 with long thick hairs. Claw simple. Metasoma semiamblypygous. Gastrocoelus indistinct. Ovipositor sheath reaching to apex of metasoma.

\section{Key to species of Gyrodonta Cameron}

1 Apical portion of flagellum cylindrical. Tooth of upper margin of mandible located subbasally. Subapical portion of clypeus with median tooth. Propodeum with costula and distinct median longitudinal carinae....................... 2

- $\quad$ Apical portion of flagellum distinctly flattened below. Tooth of upper margin of mandible located almost at middle. Clypeus without distinct tooth. Propodeum without costula, median longitudinal carinae vestigial.

G. motuoica sp.n.

Tergite 3 and subsequent tergites black, basal margins brown

G. flavomaculata Cameron

- $\quad$ Tergite 2 and subsequent tergites entirely reddish brown...G. concava (Uchida)

\section{Gyrodonta motuoica Sheng \& Riedel, sp. n.}

http://zoobank.org/75883CED-2170-4068-91D1-F5139D21B5E5

Figures 1-13

Etymology. The specific name is derived from the type locality

Material examined. Holotype, female, collected on blacklit sheet in the night by Tao Li on 10 July 2013, China: Motuo County, 1976m, Xizang Autonomous Region.

Diagnosis. Basal half of mandible longitudinally concave medially, with sparse, fine punctures; upper marginal tooth (Figure 3 ) located at center. Median longitudinal carinae of propodeum weak, incomplete, vestigial (Figure 11). Costula absent. Second tergite 1.25 times as long as apical width, with fine punctures (Figure 13). Mesosoma black, with white spots. Tergites almost entirely brownish red.

Description. Female. Body length approximately $15.0 \mathrm{~mm}$. Forewing length approximately $11.5 \mathrm{~mm}$.

Head. Face (Figure 2) slightly concave, with sparse, weak punctures; median portion with indistinct longitudinal wrinkles; upper margin with weak median triangular convexity; from outside of antennal socket to inner side of clypeal foveae with distinct oblique groove. Clypeus with different texture from face, shiny, irregularly longitudinally convex medially; subapical portion with sparse, indistinct, fine punctures; median section of apical margin almost truncate. Mandible large, basal half longitudinally concave medially, with sparse, fine punctures; upper marginal tooth (Figure 3) located at center. Malar area finely alutaceous; malar space approximately 0.9 times as long as basal width of mandible. Gena (Figures 4, 7) almost shiny, with distinct punctures, lower portion with indistinct wrinkles. Vertex with distinct, fine punctures. Interocellar 

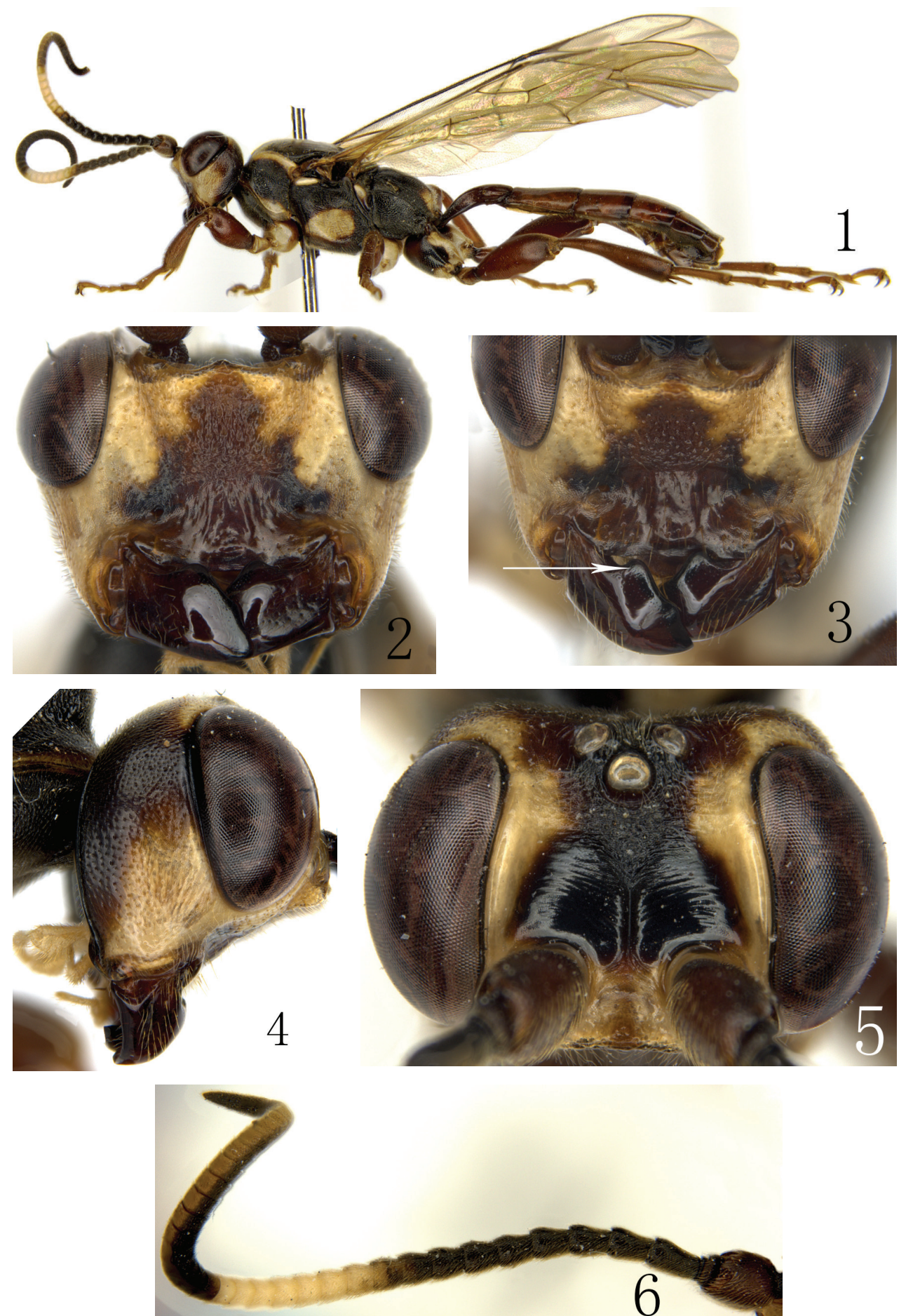

Figures I-6. Gyrodonta motuoica sp. n. Holotype. Female I Habitus, lateral view 2 Head, anterior view 3 Head, dorsal-anterior view 4 Head, lateral view 5 Frons 6 Antenna. 

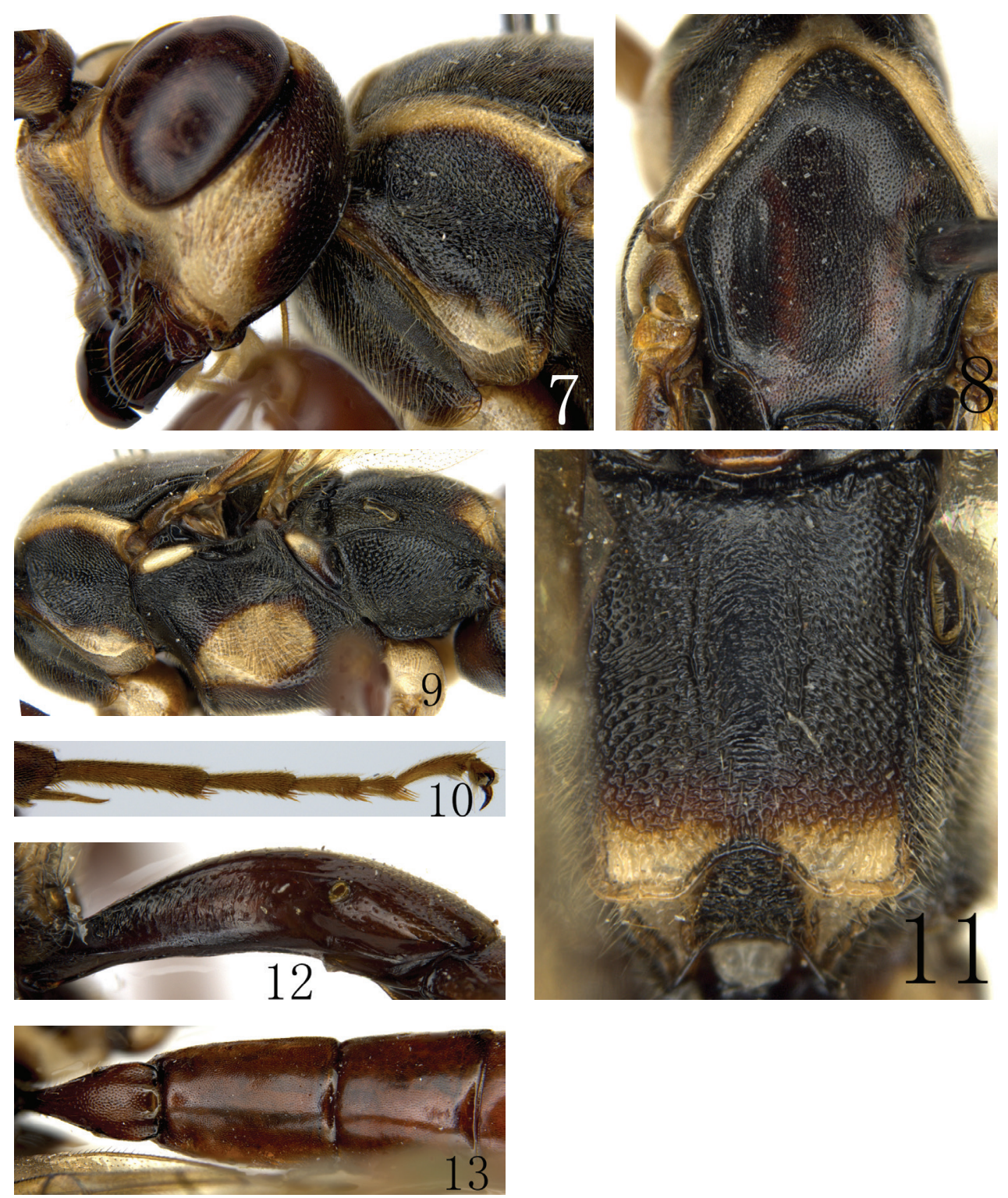

Figures 7-13. Gyrodonta motuoica sp. n. Holotype. Female 7 Head and pronotum, lateral view 8 Mesoscutum 9 Mesosoma, lateral view $\mathbf{0}$ Hind tarsus I I Propodeum $\mathbf{2}$ First tergite, lateral view I3 Tergites $1-3$, dorsal view.

area with distinct longitudinal groove. Postocellar line approximately 0.5 times as long as ocular-ocellar line, 0.87 times maximum diameter of posterior ocellus. Frons (Figure 5) deeply concave, with distinct transverse wrinkles; lower portion with distinct median longitudinal carina. Antenna (Figure 6) slightly longer than head and mesosoma combined, with 38 flagellomeres; apical portion of flagellum distinctly flattened below; ratio 
of length from first to fifth flagellomeres: 7.0:6.0:5.5:5.2:5.0. Occipital carina complete, lower end joining hypostomal carina slightly above base of mandible.

Mesosoma. Pronotum (Figure 7) with dense punctures, distance between punctures $0.2-1.5$ times their diameter; lateral concavity broad, almost shiny, upper-anterior portion with weak transverse oblique wrinkles, lower-posterior with short transverse wrinkles. Epomia strong. Mesoscutum (Figure 8) slightly convex, with dense, distinct punctures, distance between punctures 0.5-2.0 times their diameter. Notaulus absent. Scutoscutellar groove narrow, deep. Scutellum almost flat, shiny, with distinct, fine punctures, distance between punctures 0.5-3.0 times their diameter. Postscutellum transversely convex, with deep, small anterior-lateral pit. Mesopleuron (Figure 9) with fine punctures, upper-anterior, under subtegular ridge, and lower-posterior portions with transverse oblique wrinkles. Speculum with distinct punctures. Upper end of epicnemial carina not reaching anterior margin of mesopleuron. Metapleuron slightly convex, upper-anterior portion with distinct punctures, remainder with indistinct oblique wrinkles. Submetapleural carina complete, strong. Wings slightly brownish, hyaline. Fore wing with vein $1 \mathrm{cu}-\mathrm{a}$ slightly distal to $1-\mathrm{M}$, distance between them approximately as long as width of vein. Areolet pentagonal, receiving vein $2 \mathrm{~m}$-cu at middle. $2-\mathrm{Cu}$ approximately 2.0 times as long as $2 \mathrm{cu}-\mathrm{a}$. Hind wing with vein 1 -cu about 3.3 times as long as cu-a. Anterior tibia slightly compressed, anterior profile with dense thorn-like spines. Hind femur 2.8 times as long as maximum width. Hind tarsus (Figure 10) approximately 1.3 times as long as tibia. Ratio of length of hind tarsomeres 1:2:3:4:5 is 18.5:10.6:7.8:4.7:10.1. Propodeum (Figure 11) without costula, median longitudinal carinae weak, vestigial; lateral longitudinal, pleural and apical transverse carinae complete; area posteroexterna complete; area superomedia coarse, with indistinct, fine transverse wrinkles; anterior portions of lateral areas with distinct punctures, median with weak transverse wrinkles; area petiolaris with dense transverse wrinkles; area lateralis reticulate; spiracle elongate, approximately three times as long as wide.

Metasoma. First tergite approximately 3 times as long as apical width, dorsal profile of petiole with sparse punctures, lateral with indistinct longitudinal wrinkles (Figure 12). Postpetiole (Figure 13) with dense punctures, distance between punctures 0.5-2.5 times their diameter; lateral and apical portions shiny, very sparsely punctate. Second tergite (Figure 13) approximately 1.25 times as long as apical width, with fine punctures, distance between punctures 1.0-3.0 times their diameter. Third tergite approximately 0.9 times as long as apical width, with fine indistinct punctures. Ovipositor sheath reaching to apex of metasoma.

Color (Figure 1). Head mainly brownish black; face and clypeus reddish brown; inner orbits irregularly, malar area, lower portion of gena, flagellomeres (apical portion of 9) 10-16 white; median longitudinal portion of mandible, scape, apical ventral profile of flagellum dark brown. Mesosoma black. Dorsal anterior margin, upper margin and lower anterior corner of pronotum, longitudinal band of tegula, scutellum almost entirely, subtegular ridge, large median spot of mesopleuron, posterior lateral portion of propodeum white. Sublateral longitudinal band of mesoscutum dark brown. Femora, tibiae, main portion of anterior and mid coxae, anterior-basal spot of hind coxa, lower profiles 
of anterior and mid trochanters brownish red. Main portions of anterior and mid coxae, dorsal profiles of trochanters, apical margin and dorsal spot of hind coxa white. Tarsus buff. Tergites brown red. Basal portion of first tergite, hind margins of fourth and subsequent tergites more or less darkish brown. Pterostigma brown. Veins brownish black.

Remarks. This new species is similar to $G$. concava (Uchida, 1937) but can easily be distinguished from the latter by the following combination of characters: apical portion of flagellum distinctly flattened below; upper marginal tooth of mandible located at middle; propodeum without costula, median longitudinal carinae vestigial; second tergite (Figure 13) 1.25 times as long as apical width, with distinct, fine punctures. Gyrodonta concava: apical portion of flagellum cylindrical; upper marginal tooth of mandible located subbasally; propodeum with distinct costula and median longitudinal carinae; second tergite almost 1.1 times as long as apical width, finely coriaceous, without punctures.

\section{Gyrodonta flavomaculata Cameron, 1901}

Gyrodonta flavomaculata Cameron, 1901: 486.

Gyrodonta flavomaculata Cameron, 1901. Gupta 1987: 966.

Gyrodonta flavomaculata Cameron, 1901. Heinrich 1937: 265.

Gyrodonta flavomaculata Cameron, 1901. Townes, Townes and Gupta 1961: 375.

Gyrodonta flavomaculata Cameron, 1901. Yu and Horstmann 1997: 583.

\section{Specimens not examined.}

Distribution. India.

\section{Gyrodonta concava (Uchida, 1937)}

Figures 14-19

Pielia concava Uchida, 1937: 92.

Gyrodonta concava (Uchida, 1937). Townes, Townes and Gupta 1961: 375.

Gyrodonta concava (Uchida, 1937). Yu and Horstmann 1997: 583.

Diagnosis. Face without oblique groove from outside of antennal socket to inner side of clypeal foveae. Subapical portion of clypeus with median tubercle. Upper marginal tooth of mandible located at subbase. Hind portion of scutellum distinctly slanted. Hind femur (Figure 14) 3.5 times as long as maximum width. Propodeum (Figure 17) with distinct costula and median longitudinal carinae. Lateral profile of first tergite (Figure 18) with sparse, distinct punctures. Second tergite (Figure 19) almost 1.1 times as long as apical width, finely coriaceous, without punctures.

Specimen examined. 1 female, China: Mufushan, 860m, Hunan province, 27 May 2007, leg. Ze-Jian Li. 1 female, Nepal: Kosi Zone, Dhankula District, Arun 

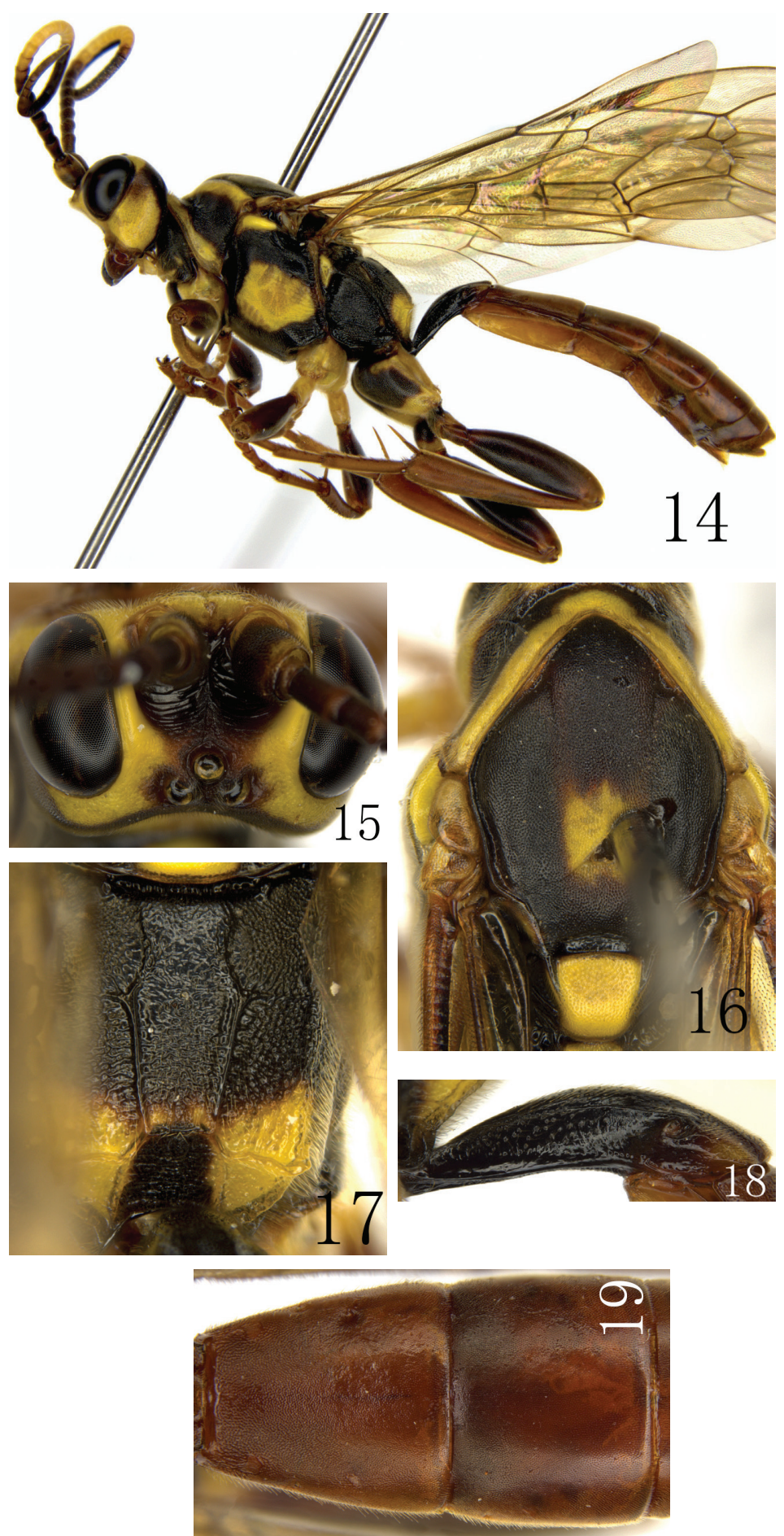

Figures I4-19. Gyrodonta concava (Uchida, 1937) Female I4 Habitus, lateral view I5 Frons 16 Mesoscutum 17 Propodeum 18 First tergite, lateral view 19 Tergites 2-3, dorsal view. 
valley, Hille Skidna Bhedetar 2000-2700 m, 24-28 May 1996, leg. P. Cechovsky (Malaise Trap) (LINZ).

Distribution. China, Nepal.

\section{Acknowledgements}

The authors are deeply grateful to Dr. Gavin Broad, Department of Life Sciences, the Natural History Museum, London, UK, and two anonymous reviewers for reviewing this manuscript. This research was supported by the National Natural Science Foundation of China (NSFC, No. 31372246, No. 31070585).

\section{References}

Cameron P (1901) Descriptions of seventeen new genera of Ichneumonidae from India and one from Australia. Annals and Magazine of Natural History 7: 480-487. doi: $10.1080 / 00222930108678502$

Gupta VK (1987) The Ichneumonidae of the Indo-Australian area (Hymenoptera). Memoirs of the American Entomological Institute 41: 1-1210.

Heinrich G (1937) A list and some notes on the synonymy of the types of the subfamily Ichneumoninae Ashmead (Hymenoptera) in the collections of the British Museum and the Hope Department of the Oxford University Museum. Annals and Magazine of Natural History (10) 20: 257-279. doi: 10.1080/00222933708655342

Heinrich GH (1967) Synopsis and reclassification of the Ichneumoninae Stenopneusticae of Africa south of Sahara (Hym.). 1. Farmington State College Press, 250 pp.

Narayanan ES, Lal K (1958) A revised classification of the Indian Ichneumonidae. Indian Journal of Entomology 20: 7-20.

Schmiedeknecht O (1902) Opuscula Ichneumonologica. I. Band. (Fasc. I.) Allgemeine Eintheilung. Die Gattungen der Joppinen, Ichneumoninen, Listrodrominen, Heresiarchinen, Gyrodontinen und Alomyinen. Bestimmungstabelle der paläarktischen Arten der Gattung Ichneumon. Blankenburg in Thüringen, 1-80.

Townes HK, Townes M, Gupta VK (1961) A catalogue and reclassification of the Indo-Australian Ichneumonidae. Memoirs of the American Entomological Institute 1: 1-522.

Uchida T (1937) Die von Herrn O. Piel gesammelten chinesischen Ichneumonidenarten. Insecta Matsumurana 11: 81-95.

Wahl DB, Mason WRM (1995) The family-group names of the Ichneumoninae (Hymenoptera: Ichneumonidae). Journal of Hymenoptera Research 4: 285-293.

Yu DS, Horstmann K (1997) A catalogue of world Ichneumonidae (Hymenoptera). Memoirs of the American Entomological Institute 58: 1-1558.

Yu DS, van Achterberg C, Horstmann K (2012) Taxapad 2012 - World Ichneumonoidea 2011. Taxonomy, Biology, Morphology and Distribution. Ottawa, Ontario, Canada. www. taxapad.com 